\title{
Optimization of in vitro culture conditions affecting propagation of mulberry plant
}

\author{
Hussein Taha ${ }^{1 *}$, Usama Mohamed Ghazy², Ahmed Mohamed Magdy Gabr ${ }^{1}$, Ahmed Ahmed Ahmed EL-Kazzaz ${ }^{1}$ \\ Eman Abdel Mottaleb Mahmoud Ahmed ${ }^{1}$ and Karima Mohamed Haggag ${ }^{3}$
}

\begin{abstract}
Background: Mulberry Morus spp. L. Family Moraceae is a perennial tree crop cultivated worldwide for foliage, fruit, fuel wood, and medicine, as well as for several other sericulture and industrial purposes. Mulberry trees are grown in more than 50 countries covering temperate, subtropical, and tropical zones as a plantation crop.

Methodology: In this study, different stages of in vitro propagation mulberry plant were investigated. In the sterilization stage, different concentrations $0.1,0.2$, and 0.3 (\%) of mercuric chloride (MC) for 10 min were used. Also, the effect of supplementation of the Murashige and Skoog (MS) medium with different concentrations 0, 0.5, 1.0, and $1.5 \mathrm{mg} / \mathrm{l}$ of BAp or TDZ on the multiplication stage was investigated. Moreover, the impact of the fortified MS medium with $1 \mathrm{mg} / \mathrm{I}$ IAA or NAA or IBA on enhancement of root system proliferation was studied. Furthermore, the effect of reculturing in vitro derived plantlets on peatmoss, perlite, and/or vermiculate for in vivo acclimatization and hardening was investigated.
\end{abstract}

Results: A simple and efficient protocol for in vitro propagation of different varieties of Morus alba (yue 11, sha $2 x$ lun 109, morittina, kokuso 27, and kantava 2) was established. Sterilization of shoot tips and auxiliary buds with $0.2 \%$ of mercuric chloride (MC) for 10 min was the best to get sterilized and survival explants. In vitro mulberry multiplication of yue 11, sha 2x lun 109, morittina, kokuso 27, and kantava auxiliary buds cultured on the MS medium fortified with $1.5 \mathrm{mg} / \mathrm{BA}$ gave the best results of the multiplication rates, maximum number of shoots/ explant, and highest shoot length $(\mathrm{cm})$, respectively. Moreover, culturing of derived mulberry shoots on the MS medium supplemented with $1 \mathrm{mg} / \mathrm{l}$ NAA enhanced totally growth figures of root system formation suitable for acclimatization and hardening of in vitro derived mulberry plants. Acclimatization and hardening successfully processed with canava 2, morittina, yue 11, sha2x, and kokuso of mulberry cultivars, respectively.

Conclusion: The described protocol in this investigation ensures a round-the-year in vitro propagation of mulberry plant with faster rate of multiplication of true-to-type plants, which will provide a useful tool for large-scale multiplication of other mulberry varieties.

Keywords: Mulberry, In vitro propagation, MS medium, Multiplication, Acclimatization

\section{Background}

Mulberry tree is an invaluable tree of immense economic importance in silk industry for its foliage, which constitutes the chief food for the silkworm, Bombyx mori L. Further, improvement of productivity traits in

\footnotetext{
*Correspondence: hussein.taha2@yahoo.com

'Plant Biotechnology Department, National Research Centre, Dokki, Giza 12311, Egypt

Full list of author information is available at the end of the article
}

mulberry plays a vital role in the progress of sericulture industry (Dandin et al., 2003; Biasiolo et al., 2004), while improvement of mulberry tree through conventional breeding has substantially contributed to the success of sericulture industry. Further, the application of biotechnology techniques in mulberry crop improvement holds a great promise especially in those areas where conventional research has not achieved the desired success (Guha et al., 2010; Dandin \& Girish, 2004). Mulberry 
tree can be vegetative propagated through stem cuttings, grafting, or budding. However, the success of these methods depends on a number of some factors such as age, genetic makeup of the plant, physiological conditions of the parental cutting, climatic conditions, and cultural practices. Furthermore, newly developed mulberry varieties cannot be immediately propagated through stem cuttings (Kapur et al., 2001). However, in vitro propagation technique allows the plant to multiply and produce thousands of plants in a short time. Also, this technique can provide plantlets throughout the year irrespective of seasonal variations. Further, in vitro propagation of mulberry is an efficient and costeffective method for rapid multiplication and production of virus-free plants in a relatively short time and limited space (Shekhawat et al., 2015). In this respect, mulberry propagation by regenerating whole plants from axillary buds of M. alba was in vitro initiated (Ohyama, 1970a). In addition, the composition of media is one of the factors that significantly affects in vitro propagation of mulberry. Among the different media compositions and plant growth regulators tested, the Murashige and Skoog medium (MS medium) (Murashige \& Skoog, 1962) supplemented with 6-benzylamino purine (BAp) was the best for shoot multiplication (Lalitha et al., 2013). Regarding mulberry root induction using biotechnology techniques, it was recommended that using half salts strength of the MS nutrient medium supplemented with NAA achieved rooting with $M$. alba, $M$. indica, $M$. $m u l$ ticaulis, and $M$. latifolia at the range of 95\% rooting (Kavyashree, 2007). However, it was reported that indole-3-butyric acid (IBA) was the best for $M$. nigra (Rao \& Bapat, 1993). In addition, implementation of higher concentrations of most auxins (> $1.0 \mathrm{mg} \mathrm{L}-1$ ) inhibited root formation in mulberry, and there is a strong interactive relationship among genotype, hormone type, and concentration (Vijayan et al., 2003). Generally, within 12-18 days after transferring shoots to the rooting media, rooting initiates were obtained (Hossain et al., 1992; Vijayan et al., 1998). Moreover, the ultimate success of in vitro propagation of mulberry on a commercial scale and low cost and with high survival rates depends on the ability to transfer plants out of culture (Chandra et al., 2010). Therefore, the present work had been planned for the achievement of the main objective: establishment of a suitable and reproducible protocol for in vitro propagation of different mulberry plant varieties.

\section{Materials and methods}

Mulberry Morus alba varieties yue 11, sha 2x lun 109, morittina, kokuso 27, and kantava 2 growing in the experimental farm of the Sericulture Research Department (SRD), Plant Protection Research, Institute Agriculture
Research Center, Giza, Egypt, were used as source materials.

\section{Sterilization stage}

In this stage, apical shoots measuring about $1.0-1.5 \mathrm{~cm}$ and lateral buds $1.0-1.5 \mathrm{~cm}$ were excised from field grown, mature, 5-year-old plants of mulberry varieties. These explants were washed thoroughly in tap water and liquid detergent soap $(5 \%, \mathrm{v} / \mathrm{v})$ for $1 \mathrm{~h}$. Then, they were washed carefully with distilled water and further rinsed in $70 \%$ ethanol for $30 \mathrm{~s}$, followed by disinfection in different concentrations of mercuric chloride (MC) $(0.1,0.2$, and $0.3 \%)$ for $10 \mathrm{~min}$ and rinsing several times in sterile distilled water to remove the traces of MC.

The following parameters were recorded as follows:

1) Percentage of contamination

2) Percentage of survival in correlation with shoot development

\section{Multiplication stage}

In this stage, sterilized apical shoots and internodes were excised and cultured on a solidified MS medium (Murashige \& Skoog, 1962) supplemented with different concentrations of cytokinins $0,0.5,1.0$, and $1.5 \mathrm{mg} / \mathrm{l}$ of 6 benzelamino purine (BAp) or thidiazuron (TDZ). Culture media were gelled by $0.7 \%$ agar added prior to autoclaving at $1.2 \mathrm{~kg} / \mathrm{cm}^{2}$ for $15 \mathrm{~min}$. The $\mathrm{pHs}$ of media were adjusted to 5.8 by the addition of $0.1 \mathrm{~N} \mathrm{HCL}$ or $0.1 \mathrm{~N}$ $\mathrm{KOH}$. The culturing was done in $350-\mathrm{ml}$ glass jars containing $50 \mathrm{ml}$ of the MS medium. The incubation was done for 28 days in a growth chamber at $26 \pm 1{ }^{\circ} \mathrm{C}$ and exposed to a 16-h/day photoperiod at intensity of 1400 lx from cool white light fluorescent lamps.

The following growth parameters were recorded as follows:

1) Percentage of shoot multiplication

2) Number of shoot/explant

3) Shoot length $(\mathrm{cm})$

\section{Rooting stage}

In this stage, derived in vitro sterilized shoots $(5 \mathrm{~cm}$ in length and about 8-12 leaves) of different Morus alba varieties were subcultured on the MS medium supplemented with $1 \mathrm{mg} / \mathrm{l}$ of indole acetic acid (IAA), naphthalene acetic acid (NAA), or indole butaric acid (IBA) to investigate those effects on root system formation.

The following parameters were recorded as follows:

1) Percentage of root formation

2) Average number of roots/shoot

3) Average of root length $(\mathrm{cm})$ 


\section{Acclimatization and hardening stage}

Acclimatization and hardening is the main target and critical process in the protocol of in vitro propagation of mulberry verities. In vitro cultured plantlets of global Morus alba varieties with well-developed roots and shoots were removed carefully from the solid medium. Then, they were washed with sterilized distilled water to remove the adherent agar medium. The harvested plantlets were then treated with $1 \%$ Bavistin solution for protection from fungal attack. The treated plants were then transferred to plastic pots $(10 \mathrm{~cm})$ containing a hardening medium.

The various hardening media were evaluated as follows:

1) Peatmoss + sand $(1: 1 \mathrm{v} / \mathrm{v})$

2) Peatmoss + sand + perlite $(1: 1: 1 \mathrm{v} / \mathrm{v})$

3) Peatmoss + sand + perlite + vermiculate $(1: 1: 1: 1 \mathrm{v} /$ v)

The potted plants were then covered with polyethylene bags to maintain humidity, temperature, and light control. The bagged plants were then incubated under the lab condition at $28{ }^{\circ} \mathrm{C}$ with $56 \%$ relative humidity for a period of 2 weeks. The perforations were introduced to plastic bags, and plants were then transferred to a greenhouse for further maintenance. After 15 days of growth in the greenhouse condition, plants were then shifted to a shade house for 1 week.

The following parameters were recorded as follows:

1) Survival percentage (\%)
2) Height of plant $(\mathrm{cm})$

3) Average number of leaves/plant

\section{Data analysis}

All experiments were designed in a completely randomized design, and obtained data were statistically analyzed using standard error (SE) according to the described method by Snedecor and Cochran (Snedecor \& Cochran, 1989).

\section{Results}

\section{Sterilization stage}

Illustrated data in Figs. 1 and 2 shows the effect of $\mathrm{HgCl}_{2}$ at different concentrations $0.1,0.2$, and 0.3 (\%) on in vitro sterilization of all used plant parts of different mulberry cultivars. The effects of these concentrations on contamination and survival percentages in association with the development of shoots were expressed. The maximum percentages of contamination (93\% and 85\%) were recorded with shoot tips and internode explants of kantava 2 cultivar treated with $0.1 \%$ of MC. However, the minimum percentages of contamination (10 and $19 \%)$ were recorded with internodes and shoot tips of kokuso27 cultivar treated with $0.3 \%$ of $\mathrm{MC}$, respectively (Fig. 1). Also, the maximum percentages of survival explants in correlation with shoot development (94 and 87\%) were recorded with all used plant parts of Morus alba c.v. kokuso 27, respectively (Fig. 2). Further, it can be mentioned that the descending order of the best results of survival explants in correlation with shoot development were recorded with Morus alba C.V.s. kokuso 27, sha $2 x$ lun 109, morittina, yu11, and kantava 2,

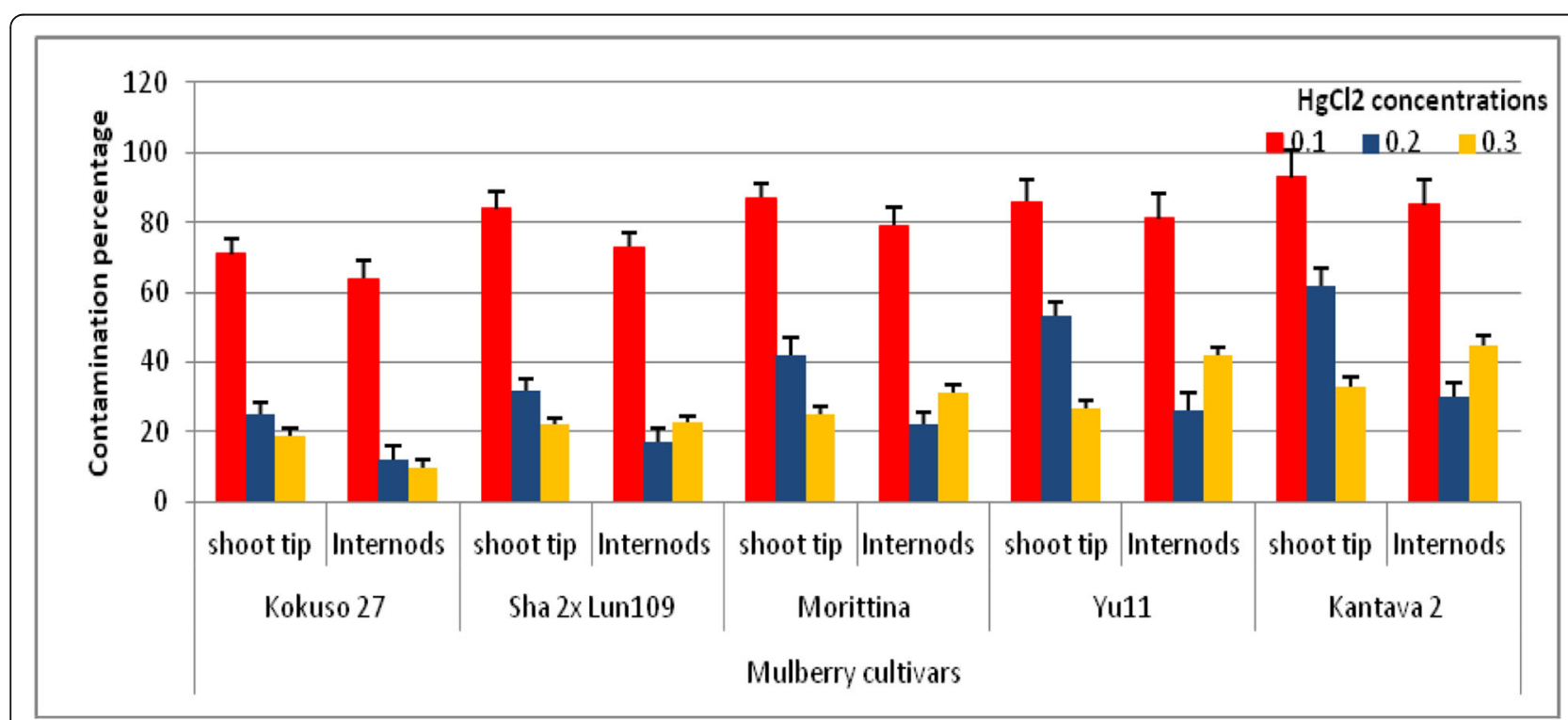

Fig. 1 Effect of sterilization treatments with $\mathrm{HgCl} 2(\mathrm{MC})$ at different concentrations $(0.1,0.2$, and $0.3 \%)$ on the percentage of contamination. Shoot tips and internodes of different mulberry cultivars were used as explants 


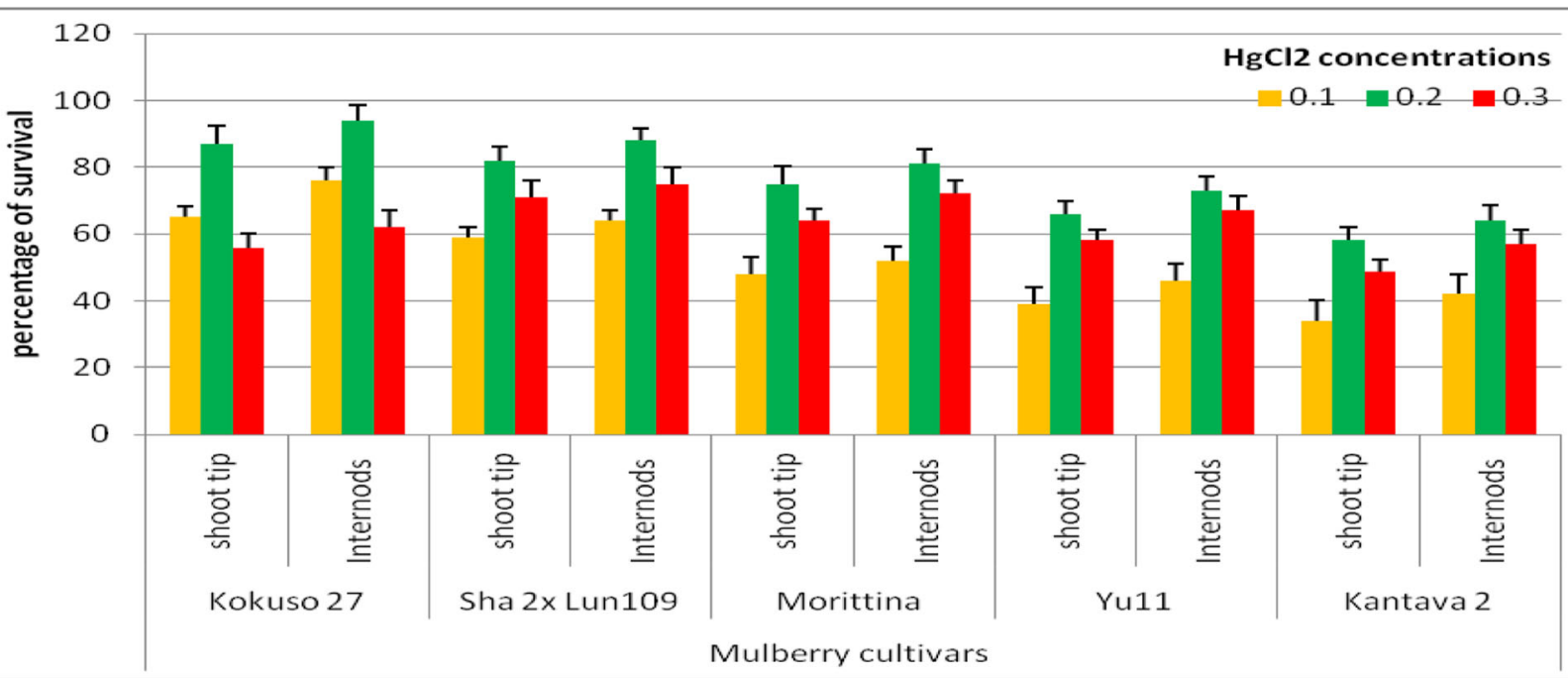

Fig. 2 Effect of sterilization treatments with $\mathrm{HgCl} 2(\mathrm{MC})$ at different concentrations $(0.1,0.2$, and $0.3 \%)$ on the percentage of survival of explants in correlation with shoot development. Shoot tips and internodes of different mulberry cultivars were used as explants

respectively. The optimum concentration of $\mathrm{MC}$ was $0.2 \%$, which recorded the minimum percentage of contamination and highly percentage of survival in correlation with shoot development. Further, it could be mentioned that $0.1 \%$ of $\mathrm{HgCl}_{2}$ are not efficient to reduce the percentage of contamination. In contrast, using $0.3 \%$ of $\mathrm{MC}$ reduced both contamination and survival percentages.

\section{Multiplication stage}

Regarding this stage, the effects of augmentation of the MS medium with BAp and TDZ at different concentrations $0,0.5,1.0$, and $1.5(\mathrm{mg} / \mathrm{l})$ on the percentage of mulberry shoot multiplication (Table 1), number of shoots/explants (Table 2), and maximum length of shoot proliferation (cm) (Fig. 3) were investigated. The highest percentages of mulberry shoot multiplication, 64.5, 48.4, 45.6, 37.6, 48.8, 39.4, 35.7, 30.8 , and 22.8 , the maximum numbers of mulberry shoots/explant, 4.05, 3.59, 3.35, 3.0, 2.54, 2.19, 1.94, $1.8,1.62$, and 1.39 , and the maximum lengths of derived shoots $(\mathrm{cm}), 6.4,5.3,4.6,4.2,3.3,5.1,4.7,4.61$, 3.8 , and 3.1, were recorded with auxiliary buds and apical meristem of kantava 2, morittina, yue 11, sha $2 \mathrm{x}$ lun 109, and kokuso 27, respectively. The optimum supplementation of the MS medium for the enhancement of shoot multiplication (\%), number of shoot/explant, and shoot length $(\mathrm{cm})$ was $1.5 \mathrm{mg} / \mathrm{l} \mathrm{BA}$ than other concentrations and utilization of TDZ.

Table 1 Effect of BA or TDZ (mg/l) at different concentrations and type of explants (apical shoots or auxiliary buds) on in vitro percentage of shoots multiplication of kantava 2, morittina,yue 11, sha 2x lun 109, and kokuso 27 mulberry cultivars

\begin{tabular}{|c|c|c|c|c|c|c|c|c|c|c|}
\hline \multirow{2}{*}{$\begin{array}{l}\text { Growth } \\
\text { regulators } \\
(\mathrm{mg} / \mathrm{l})\end{array}$} & \multicolumn{2}{|l|}{ Canava2 } & \multicolumn{2}{|l|}{ Morittina } & \multicolumn{2}{|l|}{ Yue II } & \multicolumn{2}{|c|}{ Sha 2xLun 109} & \multicolumn{2}{|l|}{ Kokuso 27} \\
\hline & $\begin{array}{l}\text { Apical } \\
\text { shoot }\end{array}$ & Axillary bud & $\begin{array}{l}\text { Apical } \\
\text { shoot }\end{array}$ & Axillary bud & $\begin{array}{l}\text { Apical } \\
\text { shoot }\end{array}$ & Axillary bud & $\begin{array}{l}\text { Apical } \\
\text { shoot }\end{array}$ & Axillary bud & $\begin{array}{l}\text { Apical } \\
\text { shoot }\end{array}$ & Axillary bud \\
\hline Free & $1.45 \pm 0.25$ & $2.5 \pm 0.35$ & $1.25 \pm 0.3$ & $2.35 \pm 0.42$ & $1.21 \pm 0.23$ & $1.75 \pm 0.42$ & $1.11 \pm 0.2$ & $1.55 \pm 0.15$ & $1 \pm 0.12$ & $1.25 \pm 0.32$ \\
\hline $0.5 \mathrm{BA}$ & $36.76 \pm 2.3$ & $\begin{array}{l}44.32 \pm \\
2.89\end{array}$ & $27.96 \pm 1.56$ & $34.56 \pm 2.3$ & $24.56 \pm 1.98$ & $\begin{array}{l}32.24 \pm \\
2.45\end{array}$ & $22.16 \pm 1.45$ & $\begin{array}{l}24.12 \pm \\
1.65\end{array}$ & $12.48 \pm 0.55$ & $\begin{array}{l}16.32 \pm \\
0.75\end{array}$ \\
\hline $1.0 \mathrm{BA}$ & $45.95 \pm 2.5$ & $55.4 \pm 3.35$ & $34.95 \pm 2.45$ & $43.2 \pm 2.25$ & $30.7 \pm 1.23$ & $40.3 \pm 3.26$ & $27.7 \pm 1.36$ & $30.15 \pm 1.5$ & $15.6 \pm 0.85$ & $20.4 \pm 1.23$ \\
\hline $1.5 \mathrm{BA}$ & $48.8 \pm 2.6$ & $64.5 \pm 3.5$ & $39.4 \pm 2.66$ & $48.4 \pm 2.35$ & $35.7 \pm 3.25$ & $45.6 \pm 3.52$ & $30.8 \pm 2.4$ & $37.6 \pm 3.2$ & $22.8 \pm 1.5$ & $33.5 \pm 3.22$ \\
\hline $0.5 \mathrm{TDZ}$ & $33.08 \pm 2.3$ & $40.5 \pm 2.35$ & $25.4 \pm 3.25$ & $\begin{array}{l}30.17 \pm \\
3.33\end{array}$ & $19.7 \pm 2.85$ & $27.8 \pm 2.43$ & $17.56 \pm 1.85$ & $20.7 \pm 3.85$ & $7.22 \pm 1.23$ & $13.5 \pm 1.75$ \\
\hline $1.0 \mathrm{TDZ}$ & $25.7 \pm 1.4$ & $\begin{array}{l}37.85 \pm \\
3.25\end{array}$ & $19.86 \pm 2.15$ & $\begin{array}{l}23.25 \pm \\
1.89\end{array}$ & $14.65 \pm 1.96$ & $\begin{array}{l}22.76 \pm \\
2.45\end{array}$ & $8.24 \pm 1.56$ & $\begin{array}{l}15.35 \pm \\
1.54\end{array}$ & $4.35 \pm 0.85$ & $\begin{array}{l}10.27 \pm \\
1.34\end{array}$ \\
\hline $1.5 \mathrm{TDZ}$ & $21.5 \pm 2.6$ & $44.3 \pm 4.12$ & $16.8 \pm 3.5$ & $30.9 \pm 2.17$ & $12.15 \pm 2.3$ & $\begin{array}{l}20.85 \pm \\
3.12\end{array}$ & $5.12 \pm 1.4$ & $13.7 \pm 1.26$ & $4 \pm 0.73$ & $9.12 \pm 1.45$ \\
\hline
\end{tabular}


Table 2 Effect of BA or TDZ (mg/l) at different concentrations and type of explants (apical shoots or auxiliary buds) on in vitro number of shoots/ explant produced from kantava 2, morittina,yue 11, sha 2x lun 109, and kokuso 27 mulberry cultivars

\begin{tabular}{|c|c|c|c|c|c|c|c|c|c|c|}
\hline \multirow{2}{*}{$\begin{array}{l}\text { Growth } \\
\text { regulators } \\
(\mathrm{mg} / \mathrm{l})\end{array}$} & \multicolumn{2}{|l|}{ Canava2 } & \multicolumn{2}{|l|}{ Morittina } & \multicolumn{2}{|l|}{ Yue II } & \multicolumn{2}{|c|}{ Sha 2xLun 109} & \multicolumn{2}{|l|}{ Kokuso 27} \\
\hline & $\begin{array}{l}\text { Apical } \\
\text { shoot }\end{array}$ & Axillary bud & $\begin{array}{l}\text { Apical } \\
\text { shoot }\end{array}$ & $\begin{array}{l}\text { Axillary } \\
\text { bud }\end{array}$ & $\begin{array}{l}\text { Apical } \\
\text { shoot }\end{array}$ & $\begin{array}{l}\text { Axillary } \\
\text { bud }\end{array}$ & $\begin{array}{l}\text { Apical } \\
\text { shoot }\end{array}$ & $\begin{array}{l}\text { Axillary } \\
\text { bud }\end{array}$ & $\begin{array}{l}\text { Apical } \\
\text { shoot }\end{array}$ & $\begin{array}{l}\text { Axillary } \\
\text { bud }\end{array}$ \\
\hline Free & $1 \pm 0$ & $1 \pm 0$ & $1 \pm 0$ & $1 \pm 0$ & $1 \pm 0$ & $1 \pm 0$ & $1 \pm 0$ & $1 \pm 0$ & $1 \pm 0$ & $1 \pm 0$ \\
\hline $0.5 \mathrm{BA}$ & $1.31 \pm 0.2$ & $2.43 \pm 0.19$ & $1.16 \pm 0.17$ & $2.15 \pm 0.14$ & $1.1 \pm 0.12$ & $2.01 \pm 0.15$ & $1 \pm 0.19$ & $1.81 \pm 0.18$ & $1 \pm 0.27$ & $1.52 \pm 0.05$ \\
\hline $1.0 \mathrm{BA}$ & $1.75 \pm 0.19$ & $3.24 \pm 0.17$ & $1.55 \pm 0.17$ & $2.87 \pm 0.15$ & $1.45 \pm 0.14$ & $2.68 \pm 0.19$ & $1.3 \pm 0.15$ & $2.41 \pm 0.18$ & $1.1 \pm 0.19$ & $2.03 \pm 0.2$ \\
\hline $1.5 \mathrm{BA}$ & $2.19 \pm 0.28$ & $4.05 \pm 0.75$ & $1.94 \pm 0.15$ & $3.59 \pm 0.16$ & $1.8 \pm 0.13$ & $3.35 \pm 0.25$ & $1.62 \pm 0.17$ & $3 \pm 0.29$ & $1.39 \pm 0.28$ & $2.54 \pm 0.14$ \\
\hline $0.5 \mathrm{TDZ}$ & $1.11 \pm 0.136$ & $2.07 \pm 0.34$ & $1 \pm 0.125$ & $1.83 \pm 0.17$ & $1 \pm 0.19$ & $1.7 \pm 0.14$ & $1 \pm 0.12$ & $1.5 \pm 0.17$ & $1 \pm 0.12$ & $1.3 \pm 0.18$ \\
\hline $1.0 \mathrm{TDZ}$ & $1 \pm 0.15$ & $1.9 \pm 0.125$ & $1 \pm 0.18$ & $1.6 \pm 0.13$ & $1 \pm 0.15$ & $1.53 \pm 0.17$ & $1 \pm 0.025$ & $1.35 \pm 0.16$ & $1 \pm 0.12$ & $1.17 \pm 0.15$ \\
\hline 1.5 TDZ & $1 \pm 0.09$ & $\begin{array}{l}1.62 \pm \\
0.123\end{array}$ & $1 \pm 0.17$ & $1.36 \pm 0.12$ & $1 \pm 0.14$ & $1.3 \pm 0.15$ & $1 \pm 0.038$ & $1.22 \pm 0.15$ & $1 \pm 0.15$ & $1 \pm 0.15$ \\
\hline
\end{tabular}

Cultures were incubated under the rhythm of light/dark condition (16/8 h). Each treatment is the average of 3 replicates \pm SE

\section{Root formation stage}

For the achievement of mulberry root system formation, the MS medium supplemented with $1 \mathrm{mg} / \mathrm{l}$ of IAA, NAA, or IBA was used. The number of initiated roots and length of root $(\mathrm{cm})$ were recorded as parameters for root system formation. As shown in Fig. 4, the maximum number of root formation/shoot 23, 18, 12, 9, and 6 roots/shoot were recorded with canava 2, morittina, yue 11 , sha $2 x$, and kokuso mulberry cultivars using the MS medium fortified with $1 \mathrm{mg} / \mathrm{l} \mathrm{NAA}$, respectively, while supplementation of the MS medium with $1 \mathrm{mg} / \mathrm{l}$ of IBA recorded $12,7,6,5$, and 3 roots/shoot with canava 2, morittina, yue 11 , sha $2 \mathrm{x}$, and kokuso mulberry cultivars, respectively. However, the minimum numbers of formed roots/shoot 7, 5, 3, 2, and 1 roots/shoot were recorded with canava 2, morittina, yue 11 , sha2x, and kokuso mulberry cultivars, respectively, using the MS medium supplemented with $1 \mathrm{mg} / \mathrm{l}$ IAA.

Regarding the other morphological characters, the descending orders of the average of root length 5.71, 4.15, $3.93,2.87$, and $1.35(\mathrm{~cm})$ were measured for the investigated mulberry cultivars canava 2, morittina, yue 11, sha2x, and kokuso, respectively. The best supplementation of the MS medium for the achievement of root length was $1 \mathrm{mg} / \mathrm{l}$ of NAA, IBA, or IAA, respectively (Fig. 5).

\section{Hardening and acclimatization stages}

In this regard, the mulberry shoot rooted plants of different mulberry cultivars were grown in pots containing

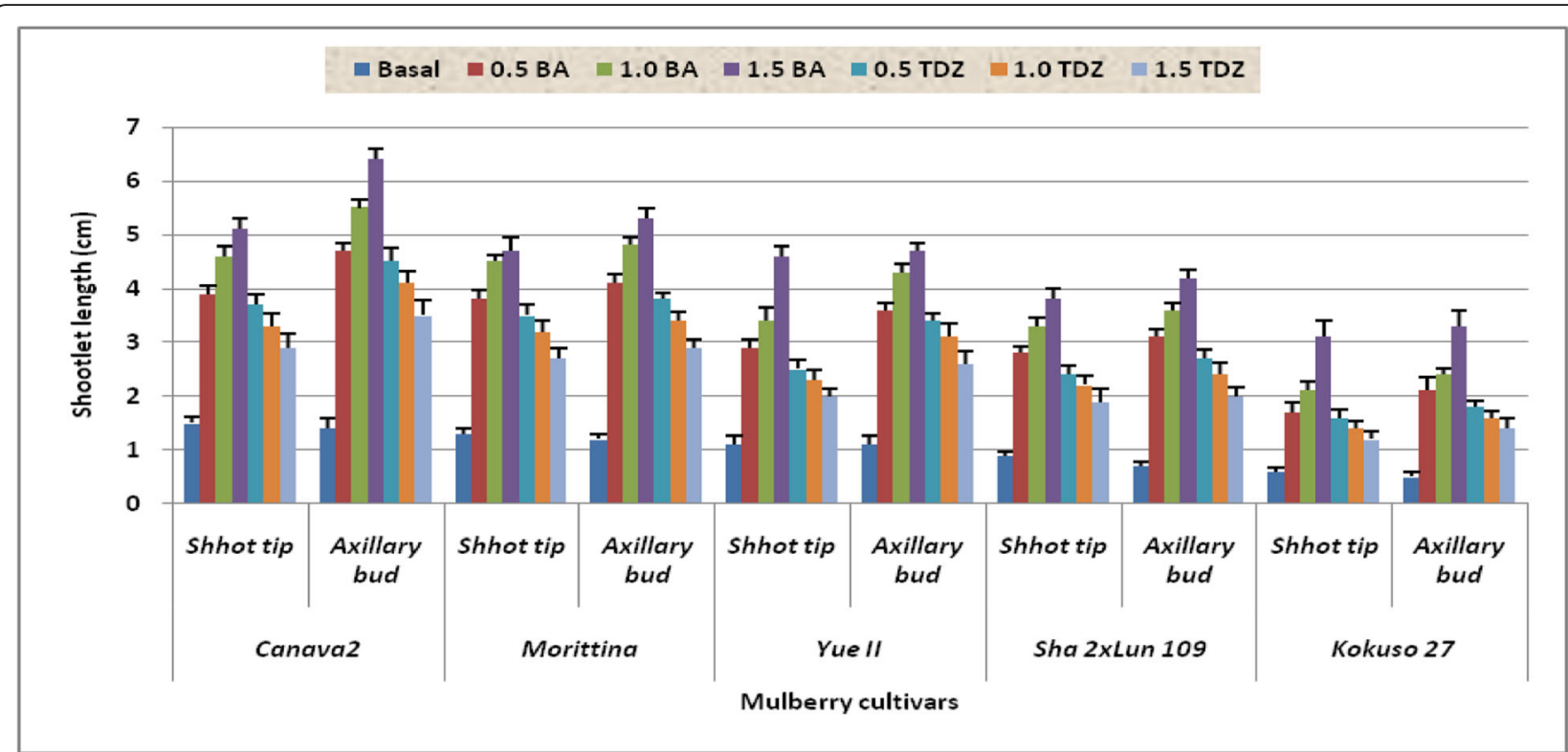

Fig. 3 Effect of BA and TDZ (mg/l) at different concentrations and type of explants (apical shoots and/or auxiliary buds) on in vitro shootlet length $(\mathrm{cm})$ of mulberry cultivars. Cultures were incubated under the rhythm of light/dark condition (16/8 h). Each treatment is the average of 3 replicates $\pm \mathrm{SE}$ 


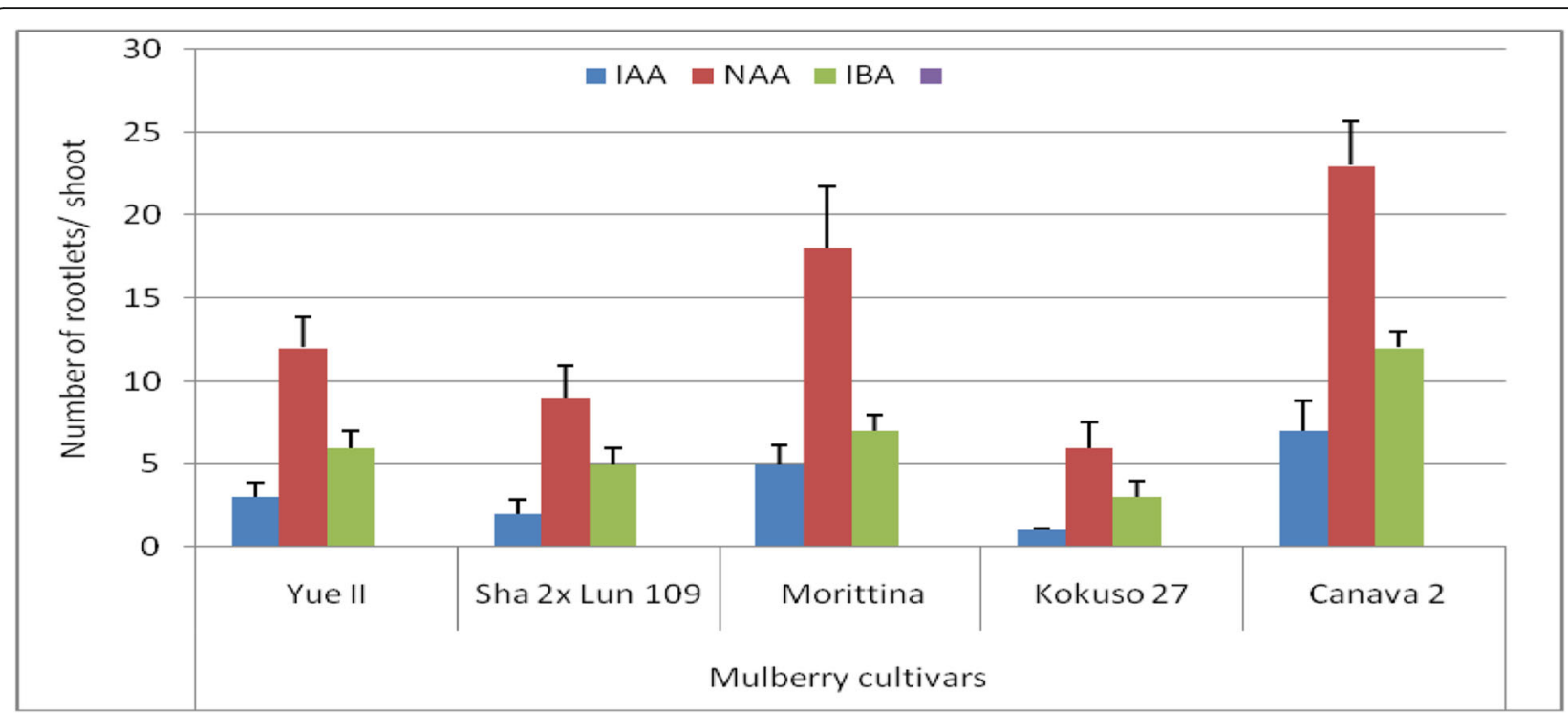

Fig. 4 Effect of the MS medium supplemented with $1 \mathrm{mg} /$ of IAA, NAA, or IBA on the number of in vitro root formation on different mulberry cultivars. Cultures were incubated under the rhythm of light/dark condition (16/8 h). Each treatment is the average of 3 replicates \pm SE

different hardening media like peatmoss + sand at the ratio of $1: 1 \mathrm{v} / \mathrm{v}$, peatmoss + sand + perlite at the ratio of $1: 1: 1 \mathrm{v} / \mathrm{v} / \mathrm{v}$, and peatmoss + sand + perlite at the ratio of $1: 1: 1: 1 \mathrm{v} / \mathrm{v} / \mathrm{v} / \mathrm{v}$; the hardened plantlets were analyzed in terms of the survival rate, length of shoot $(\mathrm{cm})$, and number of leaves/plant. In the first 4 days of transfer, the plantlets were weak. After another week of transferring, the plantlet started to acclimatize in the hardening room and started growing. Then gradually, further acclimatization had done by exposing the plantlets to greenhouse and shade house and in open light. The hardened plantlets then started to increase in height and number of leaves. Illustrated data in Fig. 6 clearly shows the influence of potting mixture media on survival and growth of different mulberry cultivars growing in vitro. The maximum percentages of survival plants, 90, 87, 67, 63 , and 54, maximum height of plants, $12,9,8,6$, and 4 $(\mathrm{cm})$, and maximum number of leaves/plant, 25, 16, 13, 9, and 3/plant, were recorded with canava 2 , morittina, yue 11, sha2x, and kokuso of mulberry cultivars, respectively.

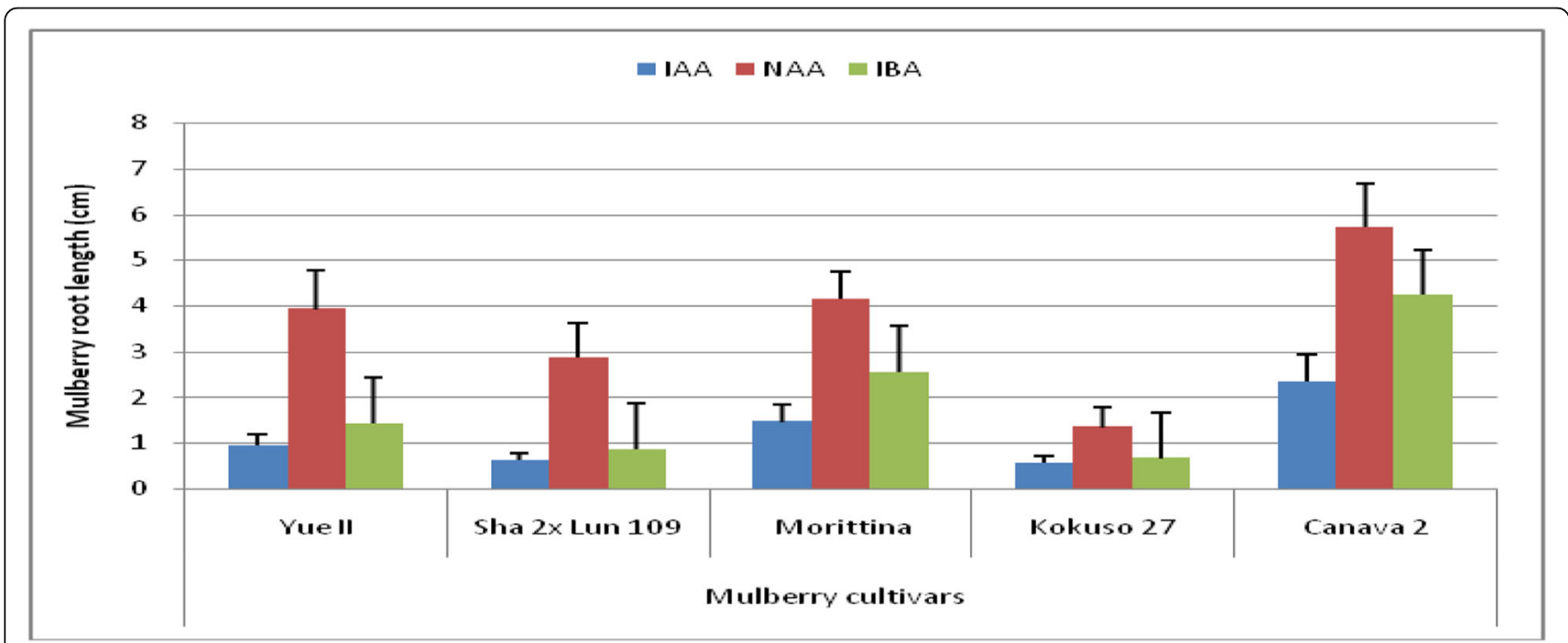

Fig. 5 Effect of MS supplemented with $1 \mathrm{mg} / \mathrm{I}$ IAA, NAA, or IBA on the average of rootlet length $(\mathrm{cm})$ of different mulberry cultivars. Cultures were incubated under the rhythm of light/dark condition (16/8 h). Each treatment is the average of 3 replicates \pm SE 


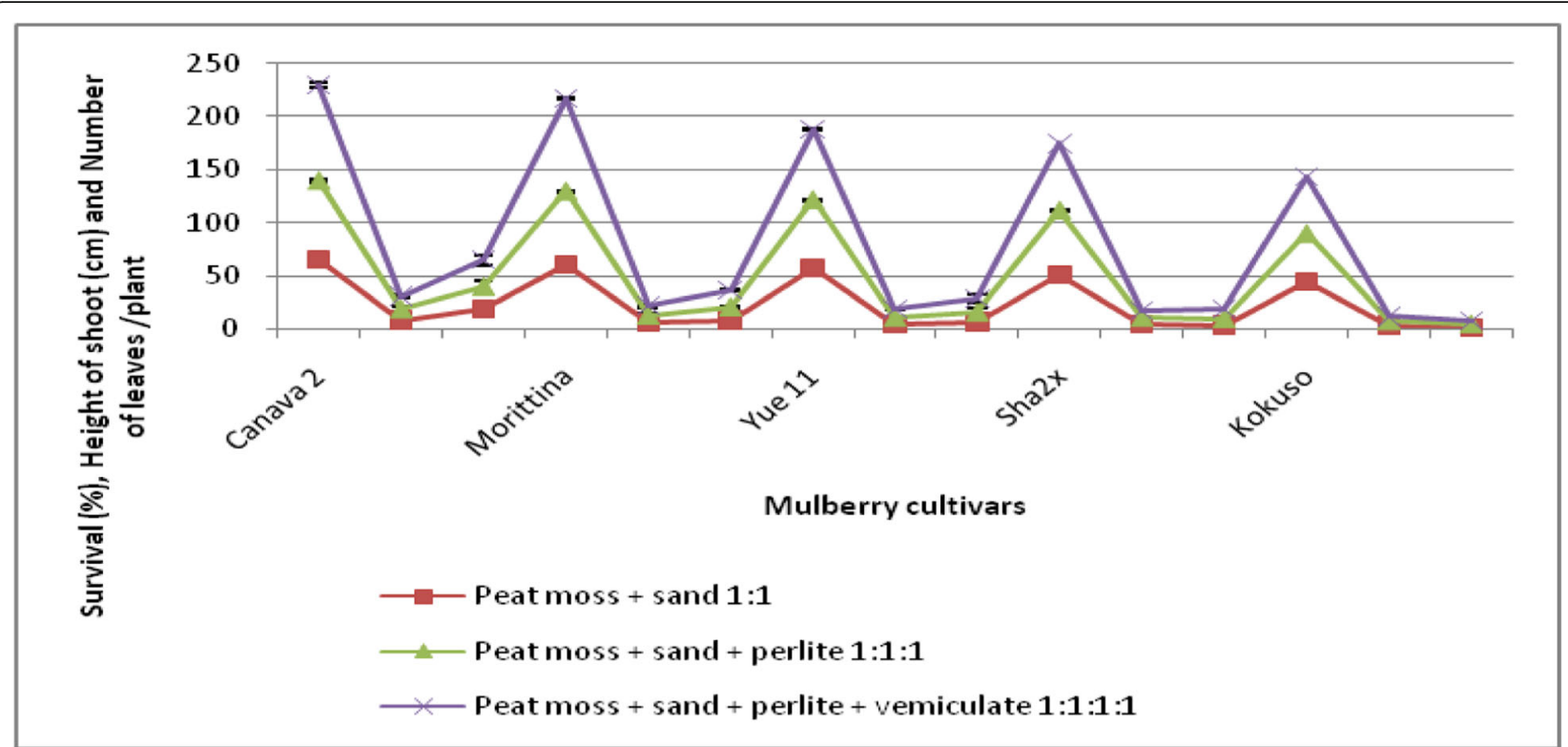

Fig. 6 Influence of different potting mixture media on the growth survival (\%), height of shoots ( $\mathrm{cm})$, and number of leaves/plant of in vitro derived mulberry cultivar plants. Each treatment is the average of 3 replicates \pm SE

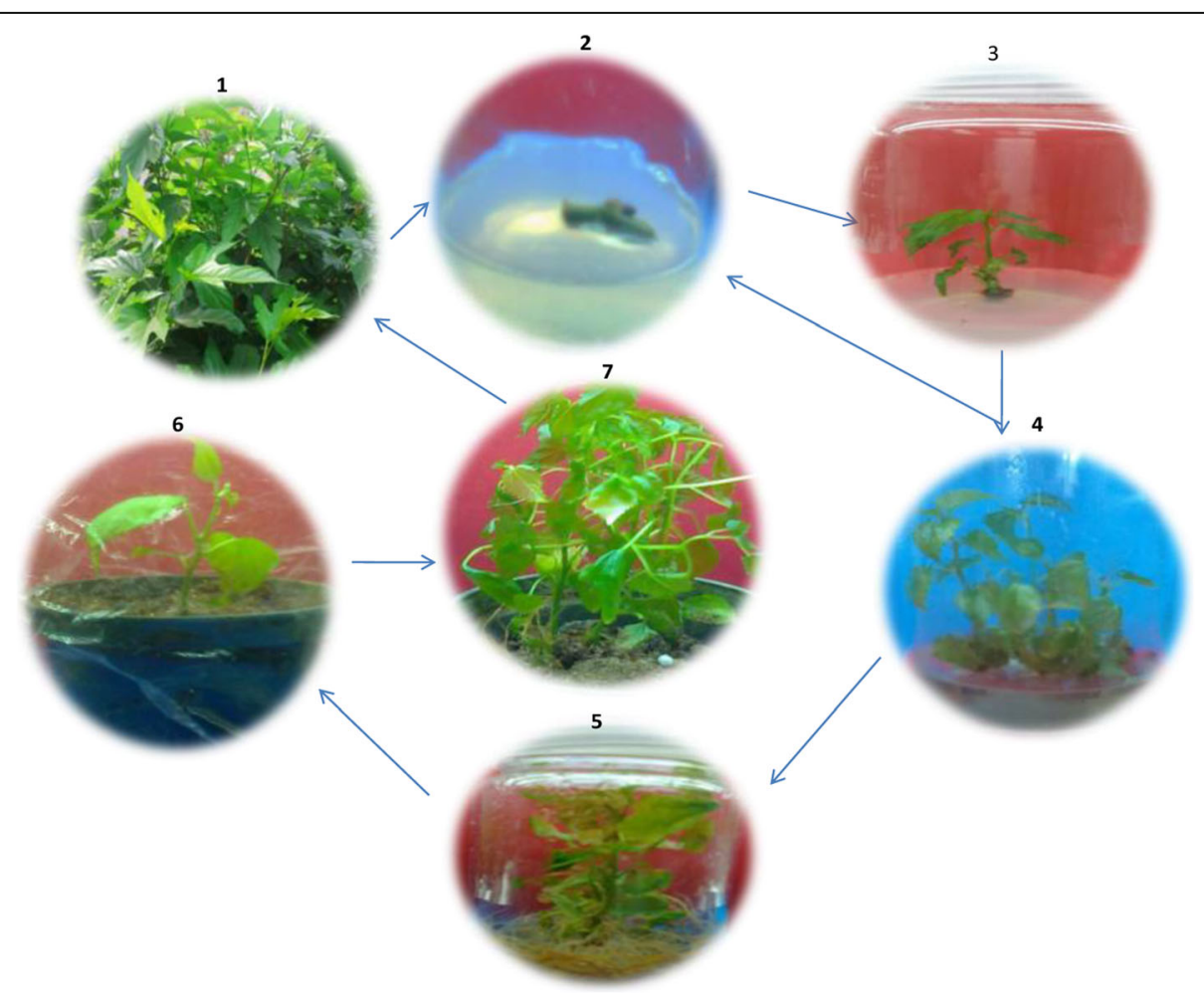

Fig. 7 Diagram of in vitro propagation of Morus alba var Canava2, showing the mulberry plant in the field (1), internode explant (2), in vitro shootlet initiation (3), multiplication (4), root formation (5), acclimatization (6), and hardening mulberry plantlets (7) 
Further, it can be recommended the peatmoss + sand + perlite at the ratio of 1:1:1:1 v/v/v/v was the best composition media for hardening of in vitro derived mulberry plants. The 3-month hardened plantlets were with many branches and healthy. Thus, the efficient in vitro rooting and hardening protocols developed in the present study can be effectively utilize for commercial cultivation of the valuable mulberry cultivar plants as shown in Fig. 7 which described the cycle of in vitro propagation of mulberry plants.

\section{Discussion}

Mulberry can be vegetative propagated through stem cuttings, grafting, or budding. However, the success of these methods depends on a number of some factors such as genetic makeup of the plant, age, physiological conditions of the parental cutting, climatic conditions, and cultural practices. Regarding in vitro sterilization of mulberry plant, it is well known that successful disinfection of explants is a pre-requisite for in vitro culture and often involves a standard set of treatments. In mulberry, $\mathrm{HgCl} 2$ and/or $\mathrm{NaOCl}$ are the most widely employed surface sterilization. Damiano et al. (Damiano \& Padro, 2008) reported that using a combination of $\mathrm{NaOCl}$ for 20 min could successfully sterilize axillary bud segments of pomegranate and mulberry resulting in 65\% explant survival. However, Kalalbandi et al. (Kalalbandi et al., 2014) showed the maximum survival (90.58\%) and minimum microbial contamination $(9.52 \%)$ on surface sterilization of pomegranate var. Bhagwa with $0.1 \%$ mercuric chloride for $10 \mathrm{~min}$. Moreover, Naik and Chand (Naik \& Chand, 2011) stated that the establishment of in vitro culture of woody plants is greatly hampered by the lethal browning of explant and culture medium at the initial establishing stage due to leaching of phenolic substances and secondary metabolites from the cut surface. Explant and medium browning is a major problem in pomegranate due to the exudation of high amount of phenols, especially in mature explants. The obtained results clearly showed that using $\mathrm{HgCl}_{2}$ at $0.2 \%$ recorded the minimum percentage of contamination and highly percentage of survival in correlation with shoot development. The obtained results are in agreement with Vijayan (Vijayan et al., 2011) who reported that contamination is one of the major problems for in vitro studies. Concerning the mulberry multiplication stage, the extracted results showed that the fortified MS medium with $1.5 \mathrm{mg} / \mathrm{l} \mathrm{BA}$ finding is more suitable for in vitro propagation of mulberry. This obtained result was close with Ohyama (Ohyama, 1970b) who mentioned that composition of media is one of the factors that significantly affect micropropagation of mulberry. Also, it was demonstrated that the MS medium containing $2 \mathrm{mgL}-$ 1 6-benzylamino purine (BAP) was the best for shoot multiplication (Lalitha et al., 2013; Bhau \& Wakhlu, 2003). Rapid multiplication of any crop plant can be achieved by inducing multiple shoots through in vitro culture. It was found that among the different concentrations of BAp or TDZ tried in the present study, the MS medium augmented with $1.5 \mathrm{mg} / \mathrm{l} \mathrm{BA}$ was the most suitable medium for auxiliary bud multiplication, resulting into 6.5 multiple shoots per explant. This is close and in agreement with the findings of Chang (Chang, 1985) in M. ihou, Ohyama and Oka (Ohyama \& Oka, 1987) in M. latifolia, and Ivanicka (Ivanicka, 1987) in M. nigra. All these studies have reported the best multiplication of apical bud on MS basal medium supplemented with different concentrations of cytokinins only. Also, a similar situation was also noticed by Santamaria (Pattnaik et al., 1996). On the other hand, Gogoi et al. (Gogoi \& Borua, 2017) reported that supplementation of the MS medium with $1.5 \mathrm{mg} / \mathrm{l}$ of gibberelic acid $\left(\mathrm{GA}_{3}\right)$ improved elongated shoots of Morus indica L. (K2- cultivar). Regarding rooting stage, it is well known that auxin regulates have various aspects of plant growth and development by affecting numerous processes including cell division, cell enlargement, and differentiation (Srivastava, 2002; Woodward \& Bartel, 2005). According to the obtained results, it could be mentioned that supplementation of the MS medium with $1 \mathrm{mg} / \mathrm{l} \mathrm{NAA}$ enhanced the root formation; the obtained results were in agreement of those obtained by Hossain et al. (Hossain et al., 1992); they reported that auxin-rich media induced rooting within 1014 days of culture in M. laevigata. Also, in several mulberry species, rooting was enhanced by treatment with NAA and IAA (Jain et al., 1990). In addition, a combination of IBA, IAA, and IPA enhanced root proliferation in $M$. australis, M. lhou, M. cathayana, and M. serrata (Woodward E Bartel, 2005; Pattnaik \& Chand, 1997). Concerning the adaptation and acclimatization stage, derived in vitro plants were kept for 3 months in a culture room, then successfully transferred to greenhouse. This obtained result was in agreement with some authors (Fila et al., 1998; Huylenbroeck et al., 1996; Bolar et al., 1998) who reported that initially the in vitro developed plants could be kept inside the culture room under sterile conditions. Then, gradually, it can be shifted to greenhouse where humidity and temperature are under control. After a couple of months, the grown plants can be shifted to shady places in the field; thereafter; it can be transplanted to field.

\section{Conclusions}

It could be mentioned that sterilization of auxiliary buds with $0.2 \%$ of mercuric chloride (MC) for $10 \mathrm{~min}$ is more efficient to get sterilized and survival explants. Regarding in vitro mulberry multiplication, it was found that culturing of auxiliary buds on the MS medium fortified with $1.5 \mathrm{mg} / \mathrm{l} \mathrm{BA}$ gave the best results of multiplication rates, maximum number of shoots/explant, and highest shoot length $(\mathrm{cm})$. Moreover, culturing of derived mulberry shoot on the MS medium supplemented with 1 
mg/l NAA enhanced totally growth figures of root system formation suitable for acclimatization and hardening of in vitro derived mulberry plantlets which successfully acclimatized by using peatmoss + sand + perlite at the ratio of 1:1:1:1 v/v/v/v.

\section{Abbreviations}

BAp: 6-Benzylamino purine; IAA: Indole acetic acid; IBA: Indole-3-butyric acid; MC: Mercuric chloride; MS medium: Murashige and Skoog medium; NAA: Naphthalene acetic acid; SE: Standard error; SRD: Sericulture Research Department; TDZ: Thidiazuron

\section{Acknowledgements}

STDF Grant for Demand-Driven Projects (STDF-DDP). The program is financed through the Ministry of State for Scientific Research and is administered by the Higher Council for Science \& Technology, Project ID 5339.

\section{Authors' contributions}

$H$. Taha designed the study and was a major contributor in writing the manuscript. U.M. Ghazy participated in the design of the study and revised the manuscript. A. M.M. Gabr participated in the analysis and interpretation of the data. A. A. A. EL-Kazzaz participated in the analysis and interpretation of the data. E.A. M. Ahmed carried out the experimental work of the manuscript. K.M. Haggag carried out the experimental work of the manuscript. The authors read and approved the final manuscript.

\section{Funding}

The study was funded by the Science and Technology Development Fund (STDF) Programm STDF Grant for Demand-Driven Projects (STDF-DDP). The program is financed through the Ministry of State for Scientific Research and is administered by the Higher Council for Science \& Technology, Project ID 5339.

\section{Availability of data and materials}

The datasets used and analyzed during the current study are available from the corresponding author on reasonable request.

\section{Ethics approval and consent to participate}

Not applicable.

\section{Consent for publication}

Not applicable.

\section{Competing interests}

The authors declare that they have no competing interests.

\section{Author details}

${ }^{1}$ Plant Biotechnology Department, National Research Centre, Dokki, Giza 12311, Egypt. ${ }^{2}$ Sericulture Research Department, Plant Protection Research-Institute, Agriculture Research Center, Giza, Egypt. ${ }^{3}$ Textile Department, National Research Centre, Dokki, Cairo, Egypt.

Received: 5 January 2020 Accepted: 2 April 2020

Published online: 22 April 2020

\section{References}

Bhau BS, Wakhlu AK (2003) Rapid micropropagation of five cultivars of mulberry. Biol. Plant. 46:349-355

Biasiolo M, Canal DAMT, Tornadore N (2004) Micromorphological characterization of ten mulberry cultivars (Morus spp.). Econ Bot. 58:639-646

Bolar JP, Norelli JL, Aldwinckle HS, Hanke V (1998) An efficient method for rooting and acclimation of micro propagated apple cultivars. Hort. Sci. 37: $1251-1252$

Chandra S, Bandopadhyay R, Kumar V, Chandra R (2010) Acclimatization of tissue cultured plantlets: from laboratory to land. Biotechnol Lett. 32(9):1199-1205

Chang JS (1985) Tissue culture of winter shoots of Baigelu mulberry (Morus ihou Koidz) trees. Sanxi Agric Sci. 3:17-18

Damiano C, Padro MDA (2008) Frattarelli, A. Propagation and establishment in vitro of myrtle (Myrtus communis L.), pomegranate (Punica granatum L.) and mulberry (Morus alba L). Propagation of Ornamental Plants. 8(1):3-8
Dandin SB, Girish Naik V. Biotechnology in mulberry (Morus spp.) crop improvement: research directions and priorities. Plant Biotechnology and Molecular Markers. 2004; pp. 206-216.

Dandin SB, Jayaswal J, Giridhar K (2003) Mulberry cultivation. In: Dandin SB, Jayaswal J, Giridhar K (eds) Handbook of sericulture technologies. Central Silk Board, Bangalore, pp 1-5

Fila G, Ghashghaie J, Hoarau J, Cornic G (1998) Photosynthesis, leaf conductance and water relations of in vitro cultured grapevine rootstock in relation to acclimatization. Physiol. Plant. 102:411-418

Gogoi G, Borua PK (2017 Jan) Al- Khayri JM. Improvement micriopropagation and in vitro fruiting of Morus indica L. (K2 cultivar). J. Genetic Eng. Biotechnol. 15(1):249-256

Guha A, Rasineni GK, Reddy AR (2010) Drought tolerance in mulberry: a physiological approach with insights to growth dynamics and leaf yield production. Exp Agric. 46:471-488

Hossain M, Rahman S M, Zaman A. Joarder OI, Islam R. Micropropagtion of M. laevigata Wall. From matured trees. Plant Cell Rep. 1992; 11: 522-524.

Huylenbroeck JM, Piqueras VA, Debergh PC (1996) Photosynthesis and carbon metabolism in leaves formed prior and during ex vitro acclimatization of micropropagated plants. Plant. Sci. 134:21-30

Ivanicka J (1987) In vitro micropropagation of mulberry, Morus nigra L. Sci Hortic (Amst) 32:33-39

Jain AK, Dandin SB, Sengupta K (1990) In vitro micropropagation through axillary bud multiplication in different mulberry genotypes. Plant Cell Reps. 8:737740

Kalalbandi BM, Waskar DP, Khandare VS, Gorad DS (2014) Micropropagation studies on pomegranate var. Bhagwa. Indian J. Hort. 71(4):564-566

Kapur A, Bhatnagar S, Khurana P (2001) Efficient regeneration from mature leaf explants of Indian mulberry via organogenesis. Sericologia 41:207-214

Kavyashree R (2007) A repeatable protocol for in vitro micropropagation of mulberry variety S54. Indian Journal of Biotechnology. 6:385-388

Lalitha N, Kih S, Banerjee R, Chattopadhya S, Saha AK, Bindroo BB (2013) High frequency multiple shoot induction and in vitro regeneration of mulberry (Morus indica L. Cv. S-1635). Int. J. Adv. Res. 1:22-26

Murashige T, Skoog F (1962) A revised medium for rapid growth and bioassays with tobacco tissue cultures. Physiol. Plant. 15:473-479

Naik SK, Chand PK (2011) Tissue culture mediated biotechnological intervention in pomegranate: a review. Plant Cell Rep. 30:707-721

Ohyama K (1970a) Tissue culture in mulberry tree. J.A.R.Q 5:30-34

Ohyama K (1970b) Tissue culture in mulberry tree. J.A.R.Q 5:30-34

Ohyama K, Oka S. Mulberry. In: Bonga, JM., Durzan, DJ. (Eds.), Cell and tissue culture in forestry, Nijhoff/Junk Publishers, Dordrecht. 1987; 3: 272-284.

Pattnaik SK, Chand PK (1997) Rapid clonal propagation of three mulberries, Morus cathayana Hemsl., M. Ihou Koiz. and M. serrata Roxb., through in vitro culture of apical shoot buds and nodal explants from mature trees. Plant Cell Report. 16:503-508

Pattnaik SK, Sahoo Y, Chand PK (1996) Micropropagation of a fruit tree, Morus australis Poir. syn. Morus acidosa Griff. Plant Cell Rep. 15:841-845

Rao PS and Bapat VA. Micropropagation of sandalwood (Santalum album L.) and mulberry (Morus indica L.). In: Ahuja MR. (Ed.), Micropropagation of woody plants Kluwer Academic Publishers. Dordrecht. 1993; 317-345.

Shekhawat M, Kannan N, Manokari M (2015) In vitro propagation of traditional medicinal and dye yielding plant Morinda coreia Buch.-Ham. South African Journal of Botany. 100:43-50

Snedecor GW, Cochran WG. (1989). Statistical methods, eighth edition, lowa State University Press.

Srivastava LM (2002) Plant growth and development: hormones and environment. Reed Elsevier India Private Limited, New Delhi, pp 341-375

Vijayan K, Chakraborti SP, Ghosh PD (2003) In vitro screening of mulberry for salinity tolerance. Plant Cell Report. 22:350-357

Vijayan K, Chakraborti SP, Roy BN (1998) Regeneration of plantlets through callus culture in mulberry. Indian J. Plant Physiol. 3:310-313

Vijayan K, Tikader A, Da Silva AJT (2011) Application of tissue culture techniques for propagation and crop improvement in mulberry (Morus spp.). Tree Forest Sci. Biotech. 5:1-13

Woodward AW, Bartel B (2005) Auxin: regulation and interaction. Ann Bot. 95: 707-735

\section{Publisher's Note}

Springer Nature remains neutral with regard to jurisdictional claims in published maps and institutional affiliations. 